\title{
Tracking hematopoietic precursor division ex vivo in real time
}

\author{
Yuchen Wang ${ }^{1,2+}$, Hong Tian ${ }^{2,3 \dagger}$, Wenzhi Cai ${ }^{2,3 \dagger}$, Zhaorui Lian², Dheeraj Bhavanasi ${ }^{4}$, Chao Wu ${ }^{2,5}$, Tomohiko Sato $^{6}$, \\ Mineo Kurokawa ${ }^{6}$, Depei $\mathrm{Wu}^{3}$, Li Fu${ }^{7}$, Hong Wang $^{8}$, Hao Shen ${ }^{9}$, Dong Liang ${ }^{10}$ and Jian Huang ${ }^{2 *}$
}

\begin{abstract}
Background: Deciphering molecular mechanisms underlying the division of hematopoietic stem cells (HSCs) and malignant precursors would improve our understanding of the basis of stem cell-fate decisions and oncogenic transformation.

Methods: Using a novel reporter of hematopoietic precursor, Evi1-GFP, we tracked the division of hematopoietic precursors in culture in real time.

Results: First, we confirmed that Evi1-GFP is a faithful reporter of HSC activity and identified three dividing patterns of HSCs: symmetric renewal, symmetric differentiation, and asymmetric division. Moreover, we found that the cytokine and growth factor combination (STIF) promotes symmetric renewal, whereas OP9 stromal cells balance symmetric renewal and differentiation of HSCs ex vivo. Interestingly, we found that Tet2 knockout HSCs underwent more symmetric differentiation in culture compared with the wild-type control. Intriguingly, OP9 stromal cells reverse the phenotype of Tet2 knockout HSCs ex vivo. Furthermore, we demonstrated that Tet2 $2^{-1} ; \mathrm{Flt} 3^{\text {ITD }}$ acute myeloid leukemia (AML) precursors primarily underwent symmetric renewal divisions in culture. Mechanistically, we demonstrated that inhibiting DNA methylation can reverse the aberrant division phenotypes of $\mathrm{Tet}^{-/-}$and $\mathrm{Tet}^{-1-} ; \mathrm{FLT3}^{\mathrm{ITD}}$ precursors, suggesting that abnormal DNA methylation plays an important role in controlling (pre-)leukemic precursor fate decision ex vivo.

Conclusions: Our study exploited a new system to explore the molecular mechanisms of the regulation of benign and malignant hematopoietic precursor division ex vivo. The knowledge learned from these studies will provide new insights into the molecular mechanisms of HSC fate decision and leukemogenesis.
\end{abstract}

Keywords: Hematopoietic stem cell-cell division, Time lapse tracking-leukemogenesis

\section{Background}

Hematopoietic stem cells (HSCs) are characterized by their self-renewal potential and ability to differentiate into multiple blood lineages. Several decades of successful HSC transplantations have demonstrated the therapeutic importance of HSCs $[1,2]$. Stem cells can undergo asymmetric and symmetric divisions, which lead to self-renewal and differentiation, but the key factors that affect this decision of HSCs remain unknown. During asymmetric division, one daughter cell remains a stem cell, while the other becomes committed. In

\footnotetext{
* Correspondence: jianh@temple.edu

${ }^{\dagger}$ Equal contributors

${ }^{2}$ Department of Pathology and Laboratory Medicine, Lewis Katz School of

Medicine, Temple University, Philadelphia, PA 19140, USA

Full list of author information is available at the end of the article
}

contrast, during symmetric divisions, a stem cell give rises to two stem cells (symmetric renewal) or two committed cells (symmetric commitment). When stem cells divide asymmetrically, tissues maintain homeostasis of stem cells while allowing a progressive increase in the number of differentiated cells. Conversely, symmetric renewal divisions result in expansion of the immature stem or precursor pool, whereas symmetric commitment divisions allow only differentiated cells to be generated $[3,4]$.

Ecotropic viral integration site 1 (EVI1) is an oncogenic transcription factor that belongs to the SET/PR domain protein family. The Evi1 locus was initially discovered as a common target of retroviral integration site in murine myeloid leukemias [5, 6]. Evi1-deficient embryos show a marked reduction in hematopoietic stem/progenitor cells 
(HSPC) in the para-aortic splanchnopleura (P-Sp) region, as well as losing their long-term repopulating capacity in vivo. In addition, HSCs in Evi1-null fetal livers are significantly reduced in number with defective multilineage reconstitution ability. Conditional deletion of Evi1 in adult mice leads to a profound loss of HSC self-renewal activity, but does not affect blood cell lineage commitment $[5,6]$. These findings suggest that EVI1 is essential for HSC selfrenewal in the fetal and adult hematopoietic system. In an elegant study of EVI1 in HSCs with a newly constructed Evil-green fluorescent protein (GFP) reporter mouse line, Kataoka et al. demonstrated that EVI1 is expressed exclusively in the HSC population in the bone marrow, and its expression marks hematopoietic cells with long-term multilineage repopulating activity [7]. Of note, the GFP knock-in to Evi1 locus does not perturb the function of Evi1 in the hematopoiesis system [7].

Ex vivo expansion of functional long-term HSCs (LTHSC) has been a challenging goal since it is not clear what intrinsic and extrinsic signals are required to control the proliferation of HSCs [8, 9]. Several publications suggest that stem cell factor (SCF), thrombopoietin (TPO), and FMS-like tyrosine kinase-3 ligand (Flt3-L) are essential for HSCs in culture [10]. Lodish and colleagues identified STIF (SCF + TPO + insulin-like growth factor (IGF)-2 + fibroblast growth factor (FGF)-1) as a HSC amplification recipe, and that this cocktail can expand mouse and human LT-HSC ex-vivo culture $[11,12]$. OP9 stromal cells are derived from op/op transgenic mice that genetically lack macrophage-colony stimulating factor (M-CSF). OP9 cells can support differentiation of embryonic stem cells to hematopoietic cells as well as maintaining HSC fate in vitro [13]. A previous study demonstrated that OP9 stromal cells direct HSCs to undergo more symmetric renewal divisions than 7 F2 stromal cells, an osteoblastic cell line isolated from $\mathrm{p} 53^{-/-}$mice [14].

Numerous studies have demonstrated that epigenetic regulators play a critical role in HSC function, especially DNA methylation [15-18]. DNA methylation patterns, typically methylated $\mathrm{CpGs}$, are established during early development. DNA methyltransferase enzymes (DNMTs) are responsible for both establishment and maintenance of these modifications throughout life. DNA demethylation is the process of removal of a methyl group from nucleotides in DNA. The ten-eleven translocation (TET) proteins TET1, TET2, and TET3 were identified as a family of cytosine dioxygenases; they are capable of converting 5-methylcytosine $(5 \mathrm{mC})$ to 5 -hydroxymethylcytosine $(5 \mathrm{hmC})$ and its derivatives, 5-formylcytosine and 5carboxylcytosine [19-21]. TET-mediated DNA demethylation has been demonstrated as one mechanism for reactivation of genes that have been transcriptionally silenced by $5 \mathrm{mC}$. It has also been speculated that $5 \mathrm{hmC}$ may function as a unique DNA modification that imparts distinct epigenetic information on the underlying genome in some contexts. The genes regulating active DNA demethylation, the TET family of enzymes, are also important for HSC function [22]. Loss of expression of Tet 2 in HSCs causes an increased primitive compartment including both stem and progenitor cells, suggesting that HSCs deficient in Tet 2 promote HSC self-renewal in vivo [23-25]. Recently, it was reported that loss of Tet2 together with Flt $3^{\text {ITD }}$ induces acute myeloid leukemia (AML) in a mouse model. Of note, this AML model has a defined leukemia stem cell (LSC) population with a characteristic transcriptional and epigenetic profile [26].

To explore the intrinsic and extrinsic signals that control HSC self-renewal and differentiation, we utilized transgenic Evi1 reporter (Evi1-GFP) mice [7], in which GFP fluorescence marks HSC activity, to harvest hematopoietic precursors. Using $\mathrm{GFP}^{+} \mathrm{HSCs}$ from the Evil-GFP mice, we have employed time-lapse microscopy to track hematopoietic precursor division in real time ex vivo. We also defined whether the rate of division and the pattern changes in the context of different treatments. We found that the STIF combination can dramatically promote symmetric renewal whereas OP9 stromal cells balance the renewal and differentiation of hematopoietic precursors ex vivo. We also found that the balance of symmetric and asymmetric division can be subverted by Tet 2 knockout and restored by OP9 stromal cells, suggesting that both extrinsic and intrinsic cues influence HSC division in culture. Furthermore, we demonstrated that Tet $^{-{ }^{-}-}$;Flt $3^{\mathrm{ITD}}$ LSCs underwent more symmetric renewal ex vivo, consistent with the concept that oncogenes promote the renewal of hematopoietic precursors [14, 27]. Our study exploited a novel system to trace the division patterns of hematopoietic precursor cells ex vivo in real time, which can be employed to investigate the intrinsic and extrinsic signaling regulation of the fate of benign and malignant hematopoietic precursors in culture.

\section{Methods}

\section{Mice}

C57BL/6 wild-type (CD45.2 ${ }^{+}$) mice were from the Jackson Laboratory. Evi1-GFP transgenic mice were generously provided by Dr. Mineo Kurokawa at the University of Tokyo [7] while Tet2 knockout (023359) and Flt3 ${ }^{\text {ITD }}$ mice (011112) were obtained from the Jackson Laboratory $[23,28]$. Mice were genotyped in-house by polymerase chain reaction (PCR). For all time-lapse imaging experiments, we used Evi1-GFP homozygous mice to detect stronger GFP signal than heterozygous mice. All mice were bred in-house in a pathogen-free mouse facility at the Temple University Lewis Katz School of Medicine. Animal experiments were 
performed in accordance with guidelines approved by the Institutional Animal Care and Use Committee (IACUC) at Temple University.

\section{Culture medium}

The base medium used was Gibco FluoroBrite ${ }^{\text {twx }}$ Dulbecco's modified Eagle's medium (DMEM; Life Technologies A18967) supplemented with 5\% fetal bovine serum (FBS), $0.01 \%$ bovine serum albumin (BSA), $10 \mu \mathrm{g} / \mathrm{ml}$ transferrin, $25 \mu \mathrm{g} / \mathrm{ml}$ insulin, $0.1 \mathrm{mM} \beta$-ME, $2 \mathrm{mMl}$-glutamine, $50 \mathrm{IU} / \mathrm{ml}$ penicillin/streptomycin, $20 \mathrm{ng} / \mathrm{ml}$ mouse SCF, $20 \mathrm{ng} / \mathrm{ml}$ mouse TPO, $20 \mathrm{ng} / \mathrm{ml}$ FLT3-L. STIF medium used was Gibco FluoroBrite ${ }^{\mathrm{Tm}}$ DMEM medium supplemented with $10 \mathrm{~g} / \mathrm{mL}$ heparin (Sigma-Aldrich, St Louis, MO), $10 \mathrm{ng} / \mathrm{mL}$ mouse SCF, $20 \mathrm{ng} / \mathrm{mL}$ mouse TPO, $20 \mathrm{ng} / \mathrm{mL}$ mouse IGF-2 (all from R\&D Systems), and 10 ng/mL human FGF-1 (Invitrogen, Frederick, MD).

\section{Fluorescence-activated cell sorting and isolation of HSCs} Bone marrow cells were flushed from the long bones (tibias and femurs) of mice with phosphate-buffered solution (PBS) without calcium or magnesium [29, 30]. For detection of LSK cells, whole bone marrow cells were incubated with phycoerythrin (PE) anti-mouse Lineage Cocktail antibody, Brilliant Violet $421^{\mathrm{m}}$-conjugated antibody to Sca1 (D7), and allophycocyanin (APC)-conjugated antibody to c-Kit (ACK2). For detection of SLAM markers, PE Cy5-conjugated antibody to CD48 (HM481) and PE Cy7-conjugated antibody to CD150 (TC1512 F 12.2) were used. All antibodies were purchased from Biolegend except for antibodies to c-Kit, which were purchased from eBioscience. Antibodies to lineage, Sca1, and c-Kit were diluted 1:100. Nonviable cells were excluded using the viability dye 7-AAD $(50 \mu \mathrm{g} / \mathrm{ml})$. Cells were sorted with a FACSAria (Becton Dickinson) automated cell sorter. Analysis was performed on FACSCanto flow cytometer (Becton Dickinson). Data were analyzed using FlowJo software (Tree Star).

\section{In vitro methylcellulose assays}

$\mathrm{GFP}^{+}$or $\mathrm{GFP}^{-}$LSK cells from Evil-GFP mice were sorted and cultured in complete methylcellulose medium (Methocult GF M3434 from StemCell Technologies). Colonies were scored after 7 days of culture and identified by morphology.

\section{In vivo analysis of HSC function}

$\mathrm{GFP}^{+}$or $\mathrm{GFP}^{-}$LSK cells from Evil-GFP mice were sorted and 100,500 , or $2500 \mathrm{GFP}^{+}$or $\mathrm{GFP}^{-}$cells were subsequently transplanted into groups of SJL (CD45.1 $\left.1^{+}\right)$ congenic mice hosts (three mice/dose). Host mice were lethally irradiated using a Cs-137 Irradiator in two equal doses of 500 rads separated by at least $2 \mathrm{~h}$. Cells were injected into the retro-orbital venous sinus of anesthetized recipient mice. All transplanted hosts are subsequently maintained on antibiotic water. Beginning 4 weeks after transplantation and continuing for at least 16 weeks, peripheral blood was collected from the tail veins of recipient mice and analyzed by FCM for the lineage markers B220 (6B2), Mac-1 (M1/70), CD4 (L3T4) and CD8 (Ly-3), and Gr-1 (8C5) to monitor engraftment. Donor and host cells were distinguished by expression of CD45.1 (A20, eBioscience) and CD45.2 (104, eBioscience) to determine the level of chimerism.

\section{Time-lapse imaging}

$\mathrm{GFP}^{+}$LSK cells from Evi1-GFP mice were sorted and cultured on glass bottomed $35-\mathrm{mm}$ petri dishes. Unattended time-lapse movies chose random $\mathrm{GFP}^{+}$ hematopoietic precursors sorted with minimal intensity fluorescent excitation, provided by camera-triggered and Uniblitz-shuttered illumination. Deltavision Softworx software was used for acquisition and processing. The blank and $\mathrm{GFP}^{+}$fields were both detected at the same time. For tracking the movies steadily and continuously, a Photometrics CoolSnap HQ high-resolution CCD camera was used. The environmental chamber surrounding the whole microscope was used for temperature and $\mathrm{CO}_{2}$ control. Over a period of $24 \mathrm{~h}$, cells were maintained at $37{ }^{\circ} \mathrm{C}, 5 \% \mathrm{CO}_{2}$, and the humidification level was saturated. A $40 \times$ objective was used for tracking $\mathrm{GFP}^{+}$cells in 15 non-overlapping wide fields to aid in cell identification. Targeted cells were observed in movie replay and analyzed by Fiji software. Criteria for scoring division patterns were set as described previously [14].

\section{Statistical analysis}

Statistical analysis was performed by unpaired Student's $t$ test. GraphPad Prism was used for statistical analysis.

\section{Results \\ Evi1-GFP is a faithful reporter of HSC activity}

To explore the mechanisms by which HSCs regulate symmetric and asymmetric division, we employed a green fluorescent protein (GFP) knock-in for the Evi1 gene in mice. With this newly constructed Evil-GFP reporter mouse line, Kataoka et al. demonstrated that EVI1 is expressed exclusively in the HSC population in the bone marrow, and its expression marks hematopoietic cells with long-term multilineage repopulating activity [7]. Consistent with their data, we found that the GFP signal correlates well with phenotypic HSCs (LSK population) in Evil-GFP mouse bone marrow. Specifically, $91.1 \%$ of $\mathrm{GFP}^{+}$cells from Evi1-GFP mice are phenotypic HSCs (LSK population) and, conversely, $68.4 \%$ of LSK cells are GFP ${ }^{+}$(Fig. 1a, b). Of note, EVI1 is expressed exclusively in the phenotypic HSC 


\section{a}

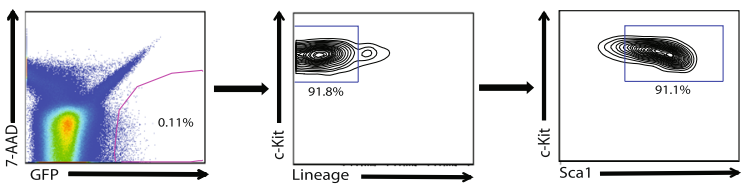

b

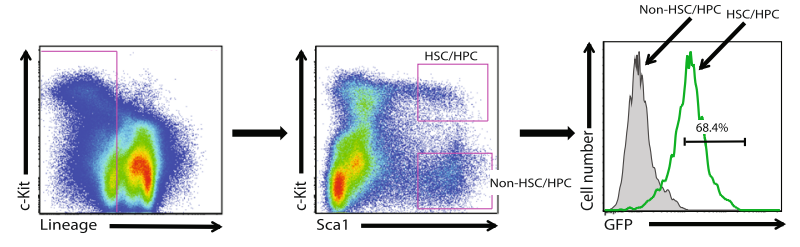

C
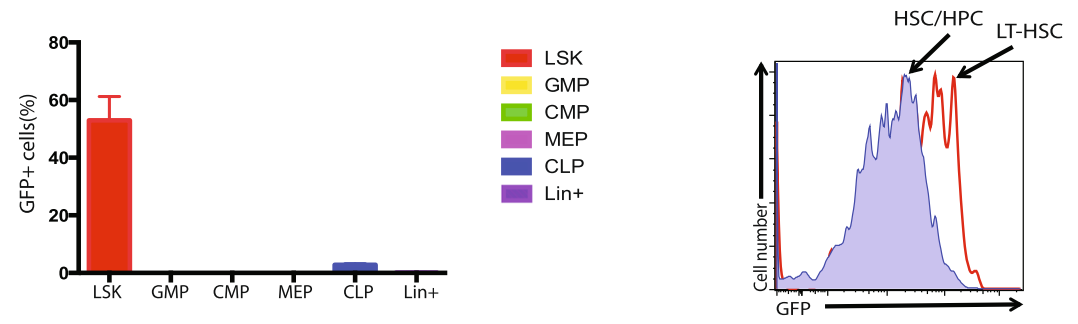

d

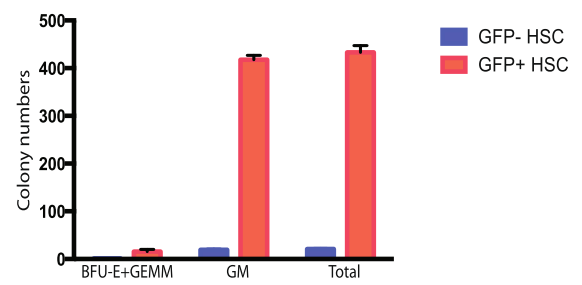

e

\begin{tabular}{|c|c|c|}
\hline & $\begin{array}{l}\text { GFP. } \\
\text {-1\% mycloid and lymphoid lineage } \\
\text { In blood }\end{array}$ & $\begin{array}{c}\text { GFP+ } \\
\text { 11\% myeloid and lymphoid lineage } \\
\text { in blood }\end{array}$ \\
\hline 100 cells & $0 / 3$ & $1 / 3$ \\
\hline 500 cells & $0 / 3$ & $3 / 3$ \\
\hline 2,500 cells & $1 / 3$ & $3 / 3$ \\
\hline
\end{tabular}

Fig. 1 Evi1-GFP is a faithful reporter for hematopoietic precursors. a Representative data from FACS analysis of green fluorescent protein (GFP) ${ }^{+}$ cells of Evi1-GFP mouse. The GFP' population was further analyzed by staining lineage, Sca1, and c-Kit markers. b Representative data from FACS analysis of bone marrow stem and progenitor populations of Evi1-GFP mouse. The GFP ${ }^{+}$populations from Lin-Sca ${ }^{+}{ }^{c}-K_{i t}{ }^{+}(\mathrm{LSK})$ and $\mathrm{Lin}^{-S c a} 1^{+} \mathrm{c}-\mathrm{Kit}^{-}$are compared. $\mathbf{c}$ (left) The quantitative analysis from FACS analysis of Evi1-GFP mouse bone marrow. The percentage of GFP ${ }^{+}$cells in LSK, GMP, CMP, CLP, and lineage positive populations is shown. (right) Representative data from FACS analysis of bone marrow stem and progenitor populations of Evi1-GFP mouse. The GFP ${ }^{+}$populations from Lin-Sca $1^{+} \mathrm{C}-\mathrm{Kit}^{+}$and $\mathrm{Lin}-\mathrm{SCa} 1^{+} \mathrm{C}-\mathrm{Kit}^{+} \mathrm{CD} 150^{+} \mathrm{CD} 48^{-}$are compared. $\mathbf{d}$ Colony formation assay (CFC) was performed with sorted GFP ${ }^{+}$cells from Evi1-GFP mouse. The number of BFU-E + GEMM (erythroid, granulocyte, erythrocyte, monocyte, megakaryocyte), GM (granulocyte, monocyte), and total colony number is shown. e The limiting dilution assay was performed to measure the number of hematopoietic stem cells (HSCs) in the GFP ${ }^{+}$population of Evi1-GFP mouse; 100, 500, and 2500 GFP $^{+}$cells from Evi1-GFP mouse were sorted and transplanted into lethally irradiated mice in combination with $3 \times 10^{5}$ recipient-derived bone marrow (BM) cells. The percentage of donor-derived cells in BM was analyzed 16 weeks after reconstitution. Chimerism greater than $1 \%$ donor-derived cells was considered positive engraftment. Values show the number of mice with positive engraftment/total mice transplanted in $\mathrm{GFP}^{-}$and $\mathrm{GFP}^{+}$groups

population, but not progenitors and lineage committed cells, in the bone marrow (Fig. 1c, left). Furthermore, higher GFP intensity was detected within the LSK fraction using SLAM family receptors (CD48 and CD150) than whole LSK population (HSC/HPC) (Fig. 1c, right), suggesting that the GFP intensity correlates with HSC property in Evi1-GFP mouse bone marrow. As a functional readout, we found that $\mathrm{GFP}^{+}$cells from Evi1-GFP mice formed 20-fold more colonies than $\mathrm{GFP}^{-}$cells in colony formation assays (Fig. 1d). Most importantly, in the gold standard bone marrow transplantation assay (limiting dilution assay), only $\mathrm{GFP}^{+}$cells from Evi1-GFP mice can repopulate lethally irradiated recipients (Fig. 1e). Collectively, our data indicate that GFP is indeed a faithful reporter of HSC activity in Evi1-GFP mouse bone marrow. Thus, the GFP signal can serve as a surrogate of HSC activity in culture, allowing us to track HSC activity ex vivo.

\section{Hematopoietic precursors undergo symmetric and asymmetric division}

To identify the division pattern of hematopoietic stem/ progenitor cells, we sorted Evi1-GFP ${ }^{+}$cells from Evi1GFP mouse bone marrow, plated them in glass- 
bottomed petri dishes, and tracked cell divisions using time-lapse inverted microscopy. Multiple $\mathrm{GFP}^{+}$cells in the dish were identified, recorded, and revisited every $10 \mathrm{~min}$ over a period of $24 \mathrm{~h}$. To track $\mathrm{GFP}^{+}$division ex vivo, we visualized the cells in both DIC and GFP and were able to detect the very bright GFP signal of hematopoietic precursors in culture (Fig. 2a). Next, we tracked multiple $\mathrm{GFP}^{+}$hematopoietic precursors dividing in culture and calculated the GFP pixel intensity unit (PIU) of the mother and daughter cells to determine the division pattern. It is well known that hematopoietic precursors are able to undergo three types of divisions: symmetric renewal, symmetric commitment, and asymmetric division (Fig. 2b). Based on the literature [14], we set the PIU ratio to 1.5 -fold as the threshold for determining whether the mother cells gave rise to two $\mathrm{GFP}^{+}$ daughter cells (symmetric renewal), two $\mathrm{GFP}^{-}$daughter cells (symmetric commitment), or one $\mathrm{GFP}^{-}$and one $\mathrm{GFP}^{+}$daughter cell (asymmetric division).

Consistent with the literature [14, 31, 32], we found that hematopoietic precursors display all three types of division ex vivo in our system. Specifically, we observed that a proportion of $\mathrm{GFP}^{+}$cells underwent symmetric renewal and they were dividing and maintaining equivalent levels of GFP in both daughters (Fig. 2c and Additional file 1: Movie S1). There were also $\mathrm{GFP}^{+}$cells that underwent symmetric commitment and the cells were dividing and downregulating GFP in both daughter cells (Fig. 2d and Additional file 2: Movie S2). Moreover, there was a small percentage of $\mathrm{GFP}^{+}$cells undergoing asymmetric division and the cells were dividing and downregulating GFP in only one daughter (Fig. 2e and Additional file 3: Movie S3). Taken together, these data indicate that hematopoietic precursors can undergo both symmetric and asymmetric divisions in our system.

We next quantitatively analyzed the pattern of hematopoietic precursors dividing under several different conditions (different concentrations of cytokines and serum). The percentage of $\mathrm{GFP}^{+}$cells dividing over $24 \mathrm{~h}$ varied from $0 \%$ to $14.8 \%$ (data not shown), suggesting that culture conditions are critical in controlling the division of HSCs. As an optimal culture condition, we chose SCF $20 \mathrm{ng} / \mathrm{ml}$, TPO $20 \mathrm{ng} / \mathrm{ml}$, and FLT3-L $20 \mathrm{ng} / \mathrm{ml}$ with 5\% serum as our base culture medium. Under this condition, the percentage of $\mathrm{GFP}^{+}$cells dividing over $24 \mathrm{~h}$ was 12.2 $\pm 2.3 \%$ from three independent experiments. Importantly, the $\mathrm{GFP}^{+}$cells underwent symmetric renewal (69.2\%), symmetric differentiation (15.4\%), and asymmetric division (15.4\%) under this condition (Fig. 3a-d).

The cytokines, growth factors, and stromal cells influence the balance of hematopoietic precursor division

Previous studies demonstrated that cytokine and growth factor combinations can expand functional HSCs in culture $[8,11,33]$. To test whether cytokines and growth factors can affect the balance of symmetric and asymmetric division ex vivo, we treated Evil-GFP ${ }^{+}$cells with STIF (SCF, TPO, IGF-2, and FGF-1) and tracked GFP $^{+}$ cells dividing for $24 \mathrm{~h}$. Previously, STIF has been shown to dramatically expand HSCs ex vivo [11]. Consistent with the published data, we found that $100 \%$ of STIFtreated $\mathrm{GFP}^{+}$hematopoietic precursors underwent symmetric renewal (Fig. 3e, f), suggesting that the precursors were expanded under this culture condition.

Previous study has shown that stromal cells can influence the pattern of hematopoietic precursors division [14]. The op/op transgenic mice-derived OP9 stromal cells directed HSCs to more symmetric renewal divisions than did 7 F2 stromal cells which were derived from $\mathrm{p} 53^{-/-}$ osteoblastic cells [14]. Intriguingly, we found that OP9 stromal cells promote HSCs/HPCs to symmetric renewal divisions with $60 \%$ of precursors undergoing symmetric renewal divisions, whereas $40 \%$ of the HSCs underwent symmetric commitment (Fig. 4a, b), suggesting that culture microenvironments can influence the balance of symmetric and asymmetric division of HSCs. Furthermore, we found that either irradiated OP9 or OP9 supernatant was able to change the dividing pattern of precursors ex vivo (Additional file 4: Figure S1a, b), suggesting that both the interaction between OP9 and HSCs and paracrine secretion from OP9 are important to direct the fate decision of precursors. Hence, future research should aim to decipher the roles of Notch and/or Wnt signaling in regulating the division of precursors in culture. Collectively, we have exploited a new reporter system for investigating the extrinsic and intrinsic factors which can influence the division pattern of hematopoietic precursors in culture.

\section{Tet2 knockout leads to more symmetric differentiation ex vivo}

Accumulating evidence has shown that TET2 plays a key role in regulating HSC function. Loss of Tet 2 can increase the self-renewal of hematopoietic precursors in vivo. Specifically, Tet2 loss leads to a progressive enlargement of the hematopoietic stem cell compartment and eventual myeloproliferation in vivo [25]. How TET2 affects hematopoietic precursor division in culture has not been studied. To address this question, we crossed Tet $2^{-/-}$mouse to Evil-GFP mouse, harvested $\mathrm{GFP}^{+}$ cells, and examined the dividing pattern of Tet 2 null hematopoietic precursors ex vivo. First, we found that the Tet 2 knockout mouse has expanded phenotypic (LSK) hematopoietic precursor compartment by flow cytometry analysis as reported previously (Additional file 5: Figure S2a). Interestingly, the Tet2 $2^{-/}$;Evil-GFP mouse maintains comparable frequency of $\mathrm{GFP}^{+}$cells to the wild-type littermates (Additional file 5: Figure S2b). When we tracked $T e t 2^{-l-} \mathrm{GFP}^{+}$precursor division in 
a
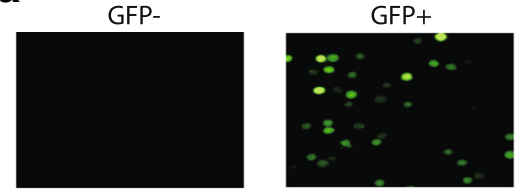

C

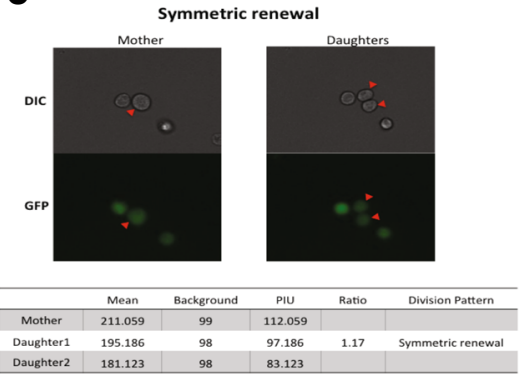

d

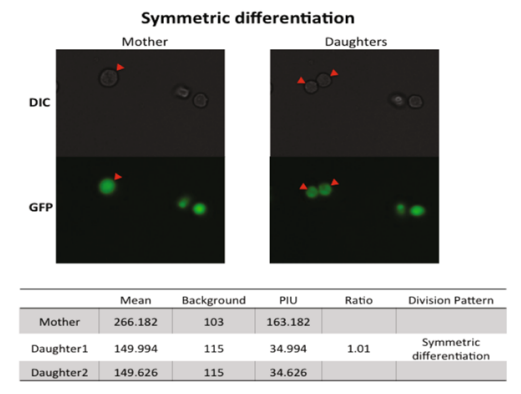

$\mathbf{e}$

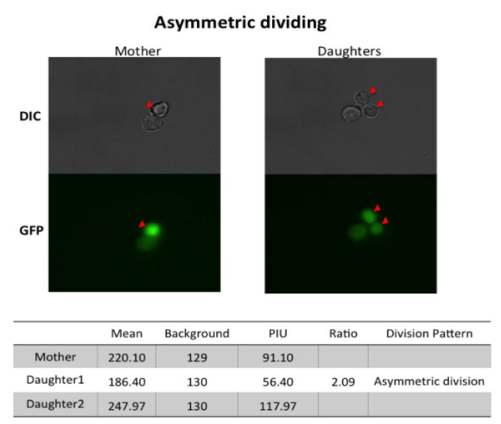

b
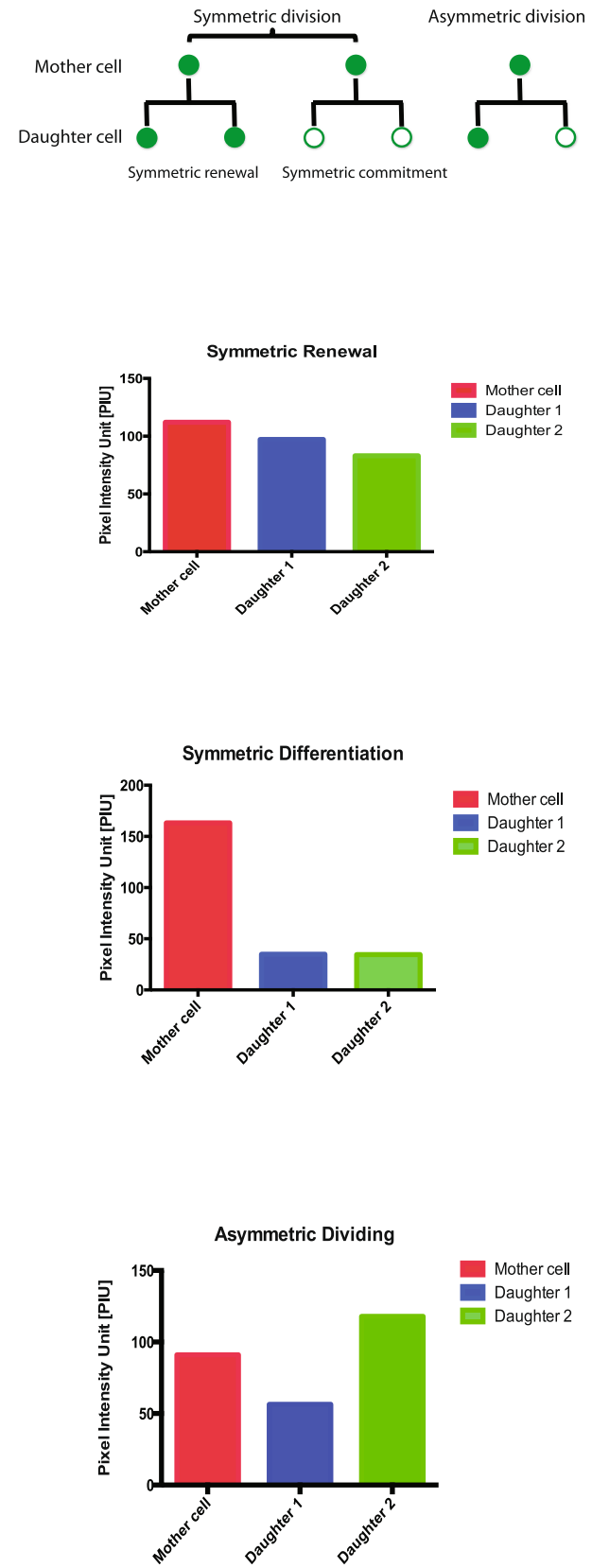

Fig. $2 \mathrm{GFP}^{+}$precursors from Evi1-GFP mouse underwent both symmetric and asymmetric division ex vivo. a Representative microscopic data are shown for green fluorescent protein (GFP) ${ }^{+}$and GFP' cells sorted from Evi1-GFP mouse bone marrow. $\mathbf{b}$ The three dividing patterns of GFP ${ }^{+}$ hematopoietic precursors. When GFP' precursors divide, they give rise to two $\mathrm{GFP}^{-}$daughter cells (symmetric commitment), two GFP' daughter cells (symmetric renewal), or one GFP' and one $\mathrm{GFP}^{+}$daughter cell (asymmetric division). c Representative microscopic data of symmetric renewal division of GFP precursors in culture. The GFP pixel intensity unit (PIU) and the ratio was calculated and is shown. The quantification of PIU of mother and daughters is shown on the right. $\mathbf{d}$ Representative microscopic data of symmetric differentiation division of GFP precursors in culture. The GFP PIU and the ratio was calculated and is shown. The quantification of PIU of mother and daughters is shown on the right. e Representative microscopic data of asymmetric division of GFP precursors in culture. The GFP PIU and the ratio was calculated and is shown. The quantification of PIU of mother and daughters is shown on the right 
a Control
Symmetric renewal
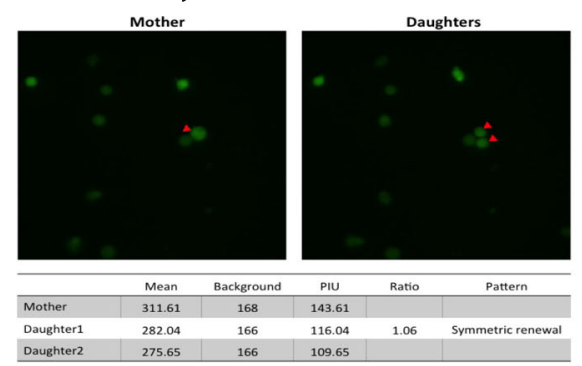

C
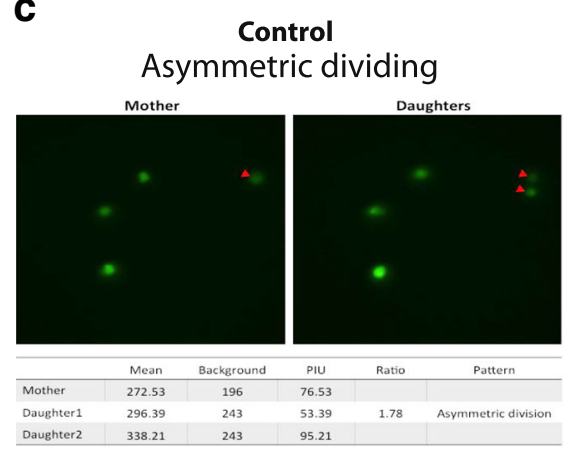

e

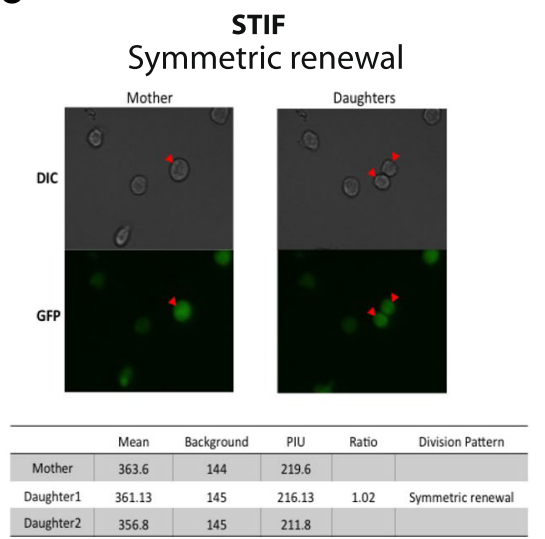

b
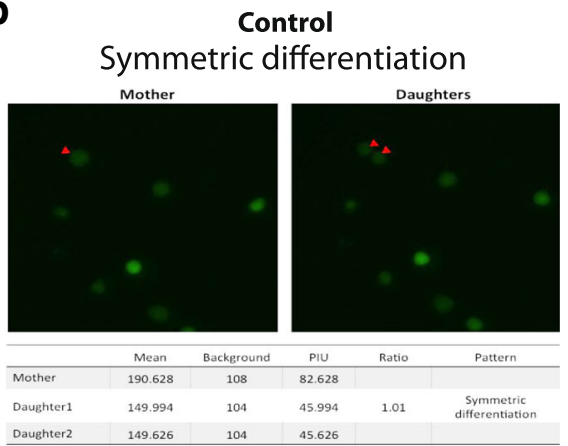

d

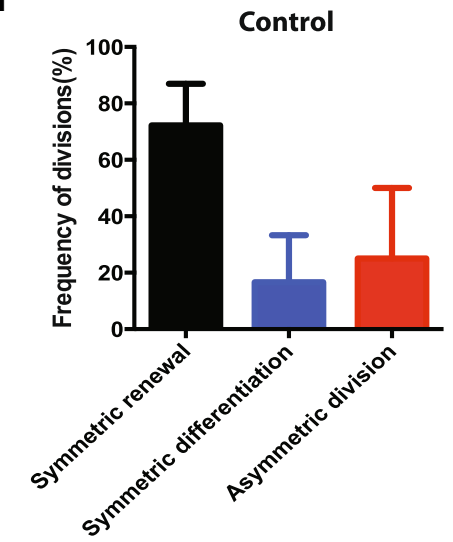

f

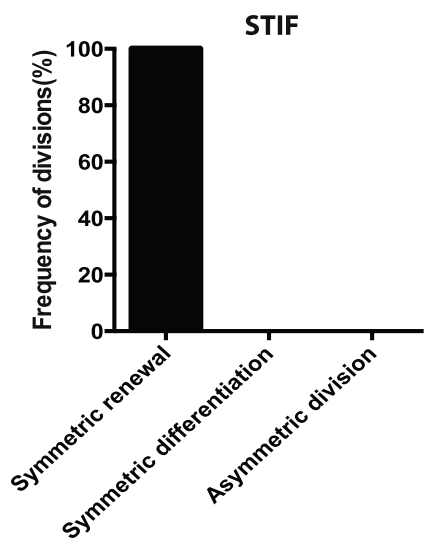

Fig. 3 Cytokines/growth factors affect the division pattern of hematopoietic precursors. a-c Representative microscopic data of symmetric renewal, symmetric differentiation, and asymmetric division of green fluorescent protein (GFP) ${ }^{+}$hematopoietic precursors harvested from Evi1-GFP mouse. The GFP pixel intensity unit (PIU) and the ratio was calculated and is shown. $\mathbf{d}$ The summary of division patterns of Evi1-GFP ${ }^{+}$precursors from three independent experiments. The frequency of symmetric self-renewal, symmetric differentiation, and asymmetric division of GFP ${ }^{+}$precursors under base conditions is shown. Error bars represent standard error of the mean (SEM). e Representative microscopic data are shown for GFP' cells treated with STIF combinations. The GFP PIU and the ratio was calculated and is shown. $\mathbf{f}$ The frequency of symmetric self-renewal, symmetric differentiation, and asymmetric division of GFP ${ }^{+}$treated with STIF (SCF + TPO + IGF-2 + FGF-1) combinations is shown. The data are a summary from three independent experiments. Error bars represent SEM

culture, we found that the ratio of symmetric renewal to symmetric differentiation division was $1: 2.5$ for Tet 2 deleted precursors (Fig. 4c). This is dramatically different from the wild-type precursors whose ratio is $7: 1$ for symmetric renewal versus symmetric differentiation (Fig. 4a), suggesting that Tet 2 null HSCs/HPCs underwent more differentiation than wild-type precursors in our culture system. Of note, we found that the 

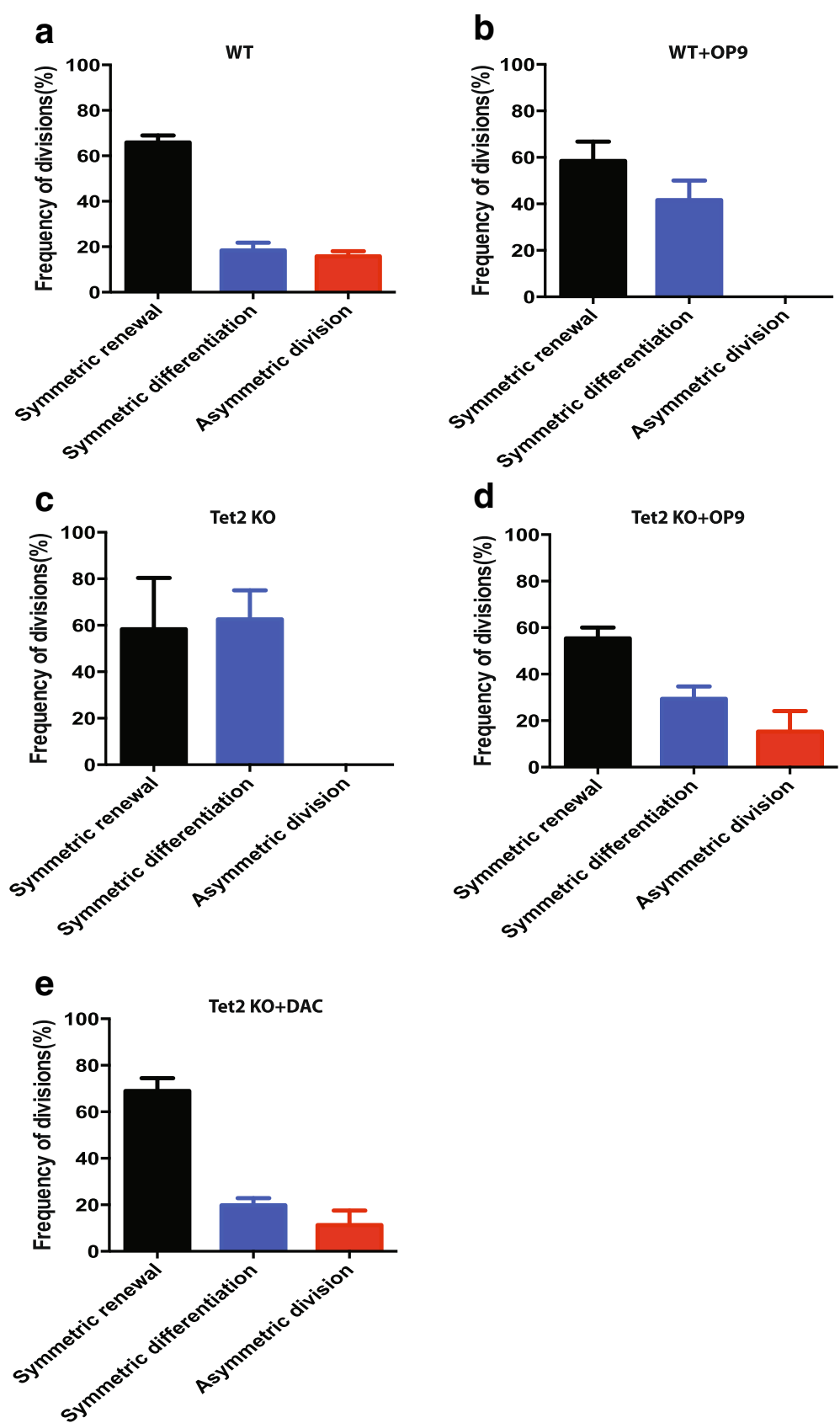

Fig. 4 Tet2 knockout hematopoietic precursors show distinct division pattern. a The frequency of symmetric self-renewal, symmetric differentiation, and asymmetric division of GFP ${ }^{+}$precursors from wild-type (WT) mouse is shown. The data are a summary from three independent experiments. Error bars represent standard error of the mean (SEM). $\mathbf{b}$ The frequency of symmetric self-renewal, symmetric differentiation, and asymmetric division of wild-type GFP ${ }^{+}$co-cultured with OP9 stromal cells is shown. OP9 stromal cells were plated in the culture dish $24 \mathrm{~h}$ before the time-lapse experiment. Then $\mathrm{GFP}^{+}$hematopoietic precursors were sorted and plated on OP9 stromal cells for tracking of the division of HSCs. The data are a summary from three independent experiments. Error bars represent SEM. c The frequency of symmetric self-renewal, symmetric differentiation, and asymmetric division of Tet2 knockout (KO) GFP ${ }^{+}$cells is shown. The data are a summary from three independent experiments. Error bars represent SEM. $\mathbf{d}$ The frequency of symmetric self-renewal, symmetric differentiation, and asymmetric division of Tet2 knockout GFP ${ }^{+}$cells co-cultured with OP9 stromal cells is shown. OP9 stromal cells were plated in the culture dish $24 \mathrm{~h}$ before the time-lapse experiment. Then $\mathrm{GFP}^{+}$hematopoietic precursors were sorted and plated on OP9 stromal cells for tracking of the division of HSCs. The data are a summary from three independent experiments. Error bars represent SEM. e The frequency of symmetric self-renewal, symmetric differentiation, and asymmetric division of Tet2 knockout GFP' cells treated with 5-aza-2'deoxycytidine (DAC) $500 \mathrm{nM}$ is shown. The data are a summary from three independent experiments. Error bars represent SEM 
fluorescence intensity of the dividing cells of Tet2 knockout was very low in comparison to wild-type littermates (Additional file 6: Figure S3a), suggesting that they are mostly progenitors. Intriguingly, co-culturing Tet 2 null hematopoietic precursors with OP9 stromal cells reversed the ratio to $3: 1$ for symmetric renewal versus symmetric differentiation (Fig. 4d), suggesting that OP9 stromal cells promote the renewal of Tet2 deleted HSC/ HPCs. Furthermore, treating Tet 2 deleted precursors with the hypomethylating agent 5-aza-2'-deoxycytidine (DAC) rescued the defect, suggesting that DNA methylation plays an important role in controlling the fate of precursors (Fig. 4e).

\section{Tet2 ${ }^{-/-} ; F L T 3^{1 T D}$ leukemia precursors primarily underwent symmetric renewal divisions ex vivo}

In a recent study, Shih et al. elegantly demonstrated that Tet $2^{-/-}$and Flt $3^{\mathrm{ITD}}$ alleles cooperate to induce AML in a mouse model. The hematopoietic precursors from this AML model have a unique transcriptional and epigenetic profiling signature [26]. To explore whether AML precursors have an aberrant cell division pattern, we crossed Tet $2^{-1-}$; $F l t 3^{\mathrm{ITD}}$ mouse to Evil-GFP mouse, harvested $\mathrm{GFP}^{+}$cells from Tet $^{-/-}$;Flt $3^{\mathrm{ITD}}$;Evi1-GFP mouse bone marrow and examined the phenotypic HSCs by flow cytometry. Furthermore, we also investigated the dividing pattern of $T e t 2^{-1-}$;Flt $3^{\mathrm{ITD}}$;Evi1-GFP hematopoietic precursors ex vivo by time-lapse microscopy. First, we found that the Tet $2^{-/-}$; Flt ${ }^{\mathrm{TTD}}$;Evi1-GFP mouse has a modest increase in the percentage of bone marrow HSCs, whereas the overall $\mathrm{GFP}^{+}$intensity was slightly reduced compared with wild-type littermates (Fig. 5a, b). Second, we observed that Tet $2^{-/-} ;$Flt $3^{\text {ITD }}$;Evi1-GFP HSC/HPCs underwent more symmetric renewal than the control (Fig. 5c, d), consistent with the concept that oncogenes can subvert the balance of symmetric and asymmetric division of precursors $[14,27]$. Being different from Tet2 null precursors, we found that the fluorescence intensity of the dividing Tet $2^{-1-}$;Flt $3^{\text {ITD }}$ precursors was comparable to wild-type littermates (Additional file 6: Figure S3b). Finally, we also assessed the effect of DAC, an inhibitor of DNA methyltransferase, on Tet $^{-/-}$;Flt $3^{\text {ITD }}$ precursor division. Our data showed that $500 \mathrm{nM}$ DAC treatment significantly reduced the frequency of precursors dividing (from $23.4 \%$ to $6.0 \%$ ) ex vivo. Moreover, DAC treatment significantly altered the dividing pattern of precursors and reduced symmetric renewal, whereas it promoted the differentiation of precursors (Fig. 5e).

Taken together, our studies have exploited a new reporter system for tracking division of hematopoietic precursors in real time and demonstrated that the balance of symmetric and asymmetric division can be influenced by extrinsic and intrinsic cues. Furthermore, we showed that leukemic precursors underwent more symmetric renewal divisions, suggesting that the aberrant symmetry of precursors is a feature of transformed cells and might be a target for leukemia therapy.

\section{Discussion}

Hematopoietic stem cell transplantation is a mainstay of therapy for hematopoietic malignancies and a variety of hereditary disorders. Understanding the regulatory mechanisms of HSC self-renewal and differentiation is important for both basic stem cell biology and improving the quality of stem cell transplantation in clinical settings [34]. To study the signaling regulation of $\mathrm{HSC} /$ HPC ex vivo, a faithful HSC-specific reporter would be very instrumental to trace HSC activity in real time in culture. In this study, we exploited a novel reporter of hematopoietic precursors, Evil-GFP, to track the division of hematopoietic precursors in culture. Consistent with a previous report [7], we demonstrated that Evi1 is expressed exclusively in the HSC population in the bone marrow and is indeed a faithful reporter of HSC activity in culture. One major advantage of the Evil-GFP reporter system is that GFP knock-in does not affect the function of the EVI1, which plays a key role in hematopoietic precursors [5-7]. With this novel reporter, we found that both cytokine and growth factor combinations as well as stromal cells direct the division pattern of HSCs ex vivo. Deletion of a critical epigenetic regulator, TET2, in HSCs changed the division pattern of HSCs in culture. Our novel HSC reporter system provides a unique tool for investigating the regulatory mechanisms of HSC self-renewal and differentiation in culture. The knowledge learned from this study might contribute to the development of a protocol for clinically applicable human HSC expansion in the future.

Using a transgenic Notch reporter (TNR) mouse line, in which GFP fluorescence indicates the status of Notch signaling, Wu et al. [14] demonstrated that hematopoietic precursor cells can undergo both asymmetric and symmetric divisions. Moreover, the stromal cells on which HSCs have been placed also affect the pattern of division. Furthermore, it was nicely demonstrated that oncogenes can also influence the balance of symmetric and asymmetric division [14]. This conclusion is consistent with the idea that symmetric and asymmetric cell division is an essential mechanism of balancing self-renewal and differentiation of HSCs. The major issue with this study is that it is quite controversial whether this notch reporter is a specific reporter of HSC activity in bone marrow $[35,36]$.

How stem cells divide has been extensively studied. The best example of symmetric and asymmetric division is the dividing of precursor cells in invertebrates. In the Drosophila germline, when a stem cell divides asymmetrically it is always the cell close to the "hub cell" that remains a stem cell while the other differentiates. It is 


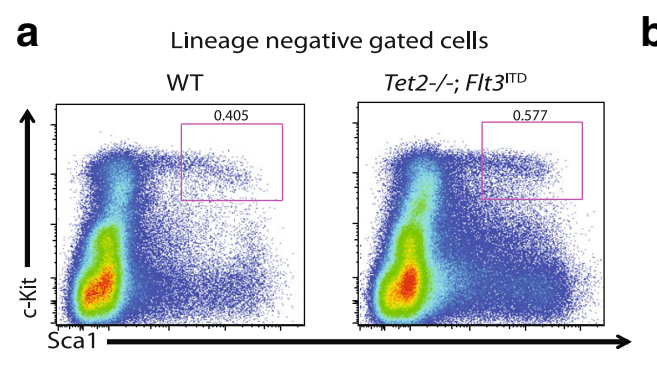

b Lin-c-Kit+Sca1+ gated cells
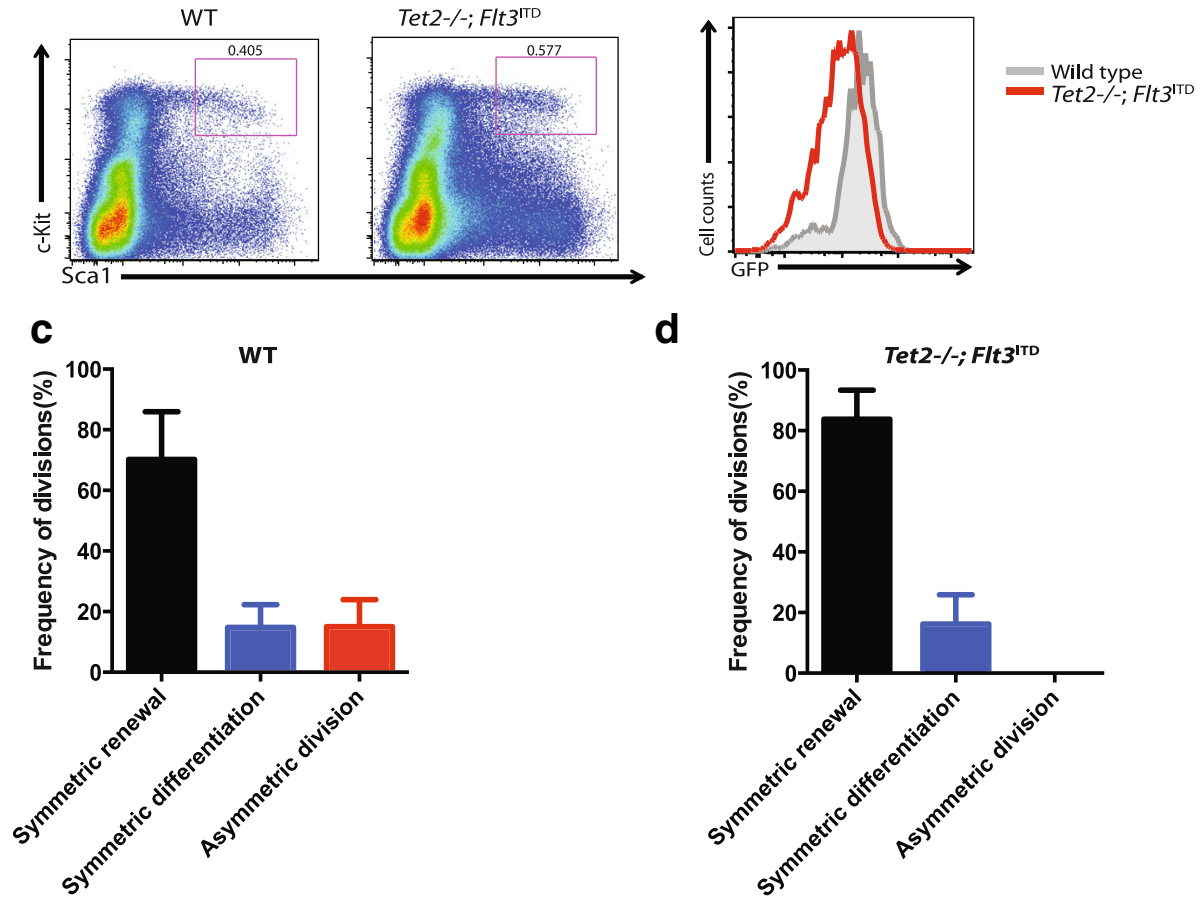

d
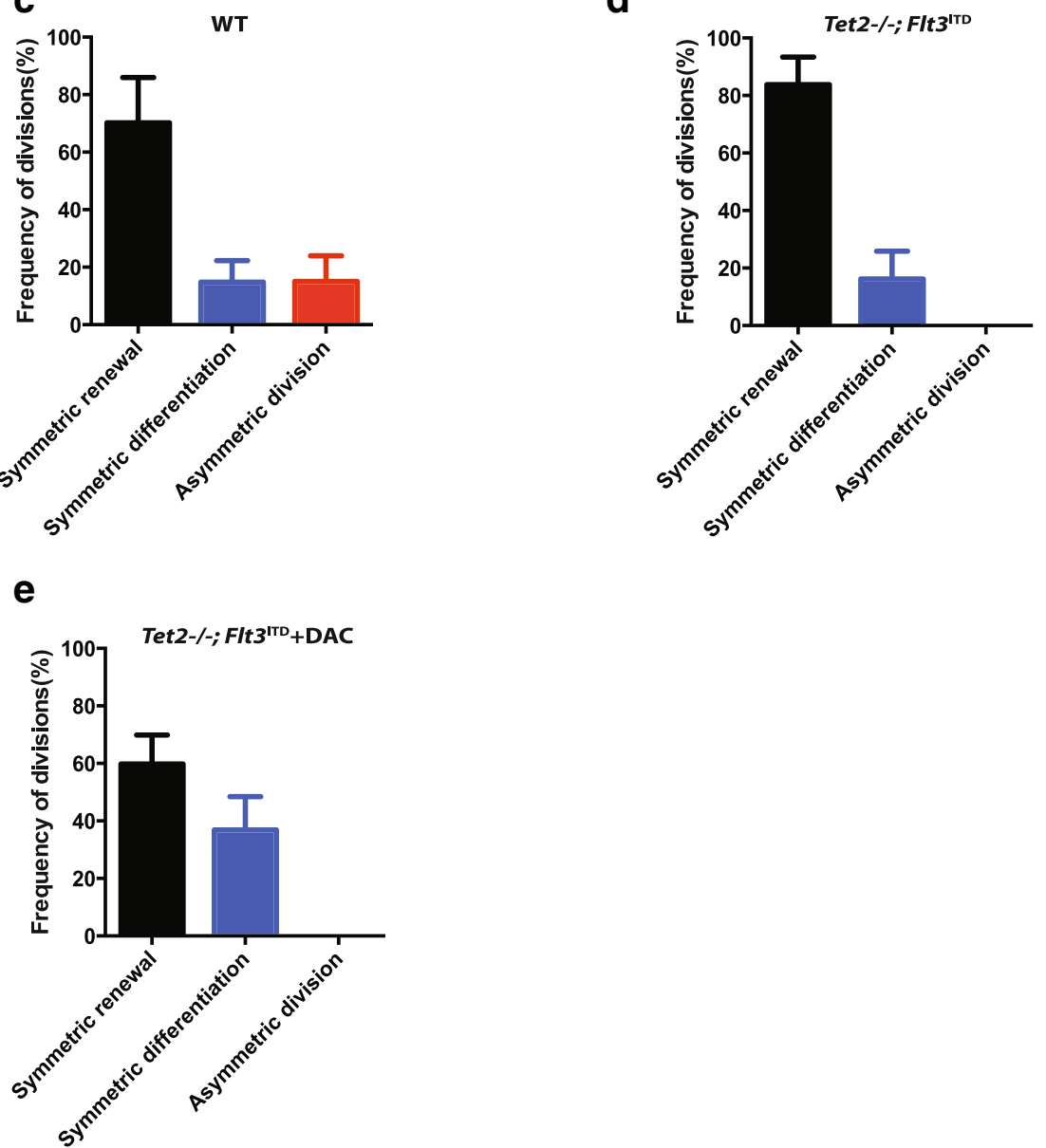

Fig. $5 \mathrm{Tet}^{-1-} ; \mathrm{Flt} \mathrm{r}^{\mathrm{TD}}$ hematopoietic precursors underwent primarily symmetric renewal ex vivo. a Representative data from FACS analysis of wild-type (WT) Evi1-GFP and Tet2 ${ }^{-1}$; Flt $3^{\text {ITD }}$;Evi1-GFP HSCs. The cells were stained with antibodies to lineage, Sca1, and c-Kit markers. The lineage negative population was gated first. Numbers indicate percent cells within Lin-C-Kit ${ }^{+} S c a 1^{+}$gates. $\mathbf{b}$ Representative FACS data from GFP ${ }^{+}$population from wild-type and Tet2

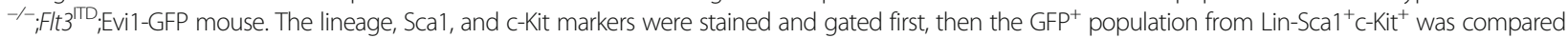
with wild-type Evi1-GFP and Tet2 ${ }^{-1} ;$; Flt3 $3^{\text {TD }} ;$ Evi1-GFP mouse. $\mathbf{c}$ The frequency of symmetric self-renewal, symmetric differentiation, and asymmetric division of GFP' from wild-type Evi1-GFP mouse bone marrow is shown. The data are a summary from three independent experiments. Error bars represent standard error of the mean (SEM). $\mathbf{d}$ The frequency of symmetric self-renewal, symmetric differentiation, and asymmetric division of GFP ${ }^{+}$cells from Tet2 ${ }^{-1} ;$;Flt $3^{\text {ITD }}$;Evi1-GFP compound mouse is shown. The data are a summary from three independent experiments. Error bars represent SEM. e The frequency of symmetric self-renewal, symmetric differentiation, and asymmetric division of $500 \mathrm{nM} 5$-aza-2'-deoxycytidine (DAC) treated GFP ${ }^{+}$cells from Tet2 ${ }^{-1-} ; F / 3^{\text {TID }}$;Evi1-GFP compound mouse is shown. The data are a summary from three independent experiments. Error bars represent SEM

suggested that a signal from the hub is critical to determine the fate of the dividing cells, for example the unpaired ligand [37, 38]. Another example is in the Drosophila nervous system; the neuroblast divides along its apical basal axis such that the apical daughter remains a neuroblast and the basal daughter becomes a ganglion mother cell that generates differentiated progeny [39]. It also has been reported that two stem cells from the Caenorhabditis elegans germline can divide to become several thousand germ cells through a series of 
symmetric divisions [40]. It has been documented that there is a similar division pattern in most mammalian systems, including the hematopoiesis system. Asymmetric fates of the progeny of mammalian hematopoietic precursor cells have been described previously in a number of elegant studies using paired daughter cell analyses and microscopic time-lapse imaging [41-43]. It has also been demonstrated that the frequency of these asymmetric fate decisions can be influenced by extrinsic signals provided by the type of stromal or cytokines used in culture $[14,44]$. Our data are very consistent with the literature that mammalian stem cells can undergo asymmetric and symmetric division. Extrinsic signals, e.g., cytokines and growth factors, can control the balance of symmetric and asymmetric division. Recent studies reported ex vivo expansion of hematopoietic stem and progenitor cells using cytokine cocktails combined with an array of factors, including Musashi-2, Pyrimidoindole derivatives (UM171), aryl hydrocarbon receptor antagonists (SR1), Wnt activators, Notch ligands, angiopoietinlike proteins, prostaglandin E2, pleiotrophin, and GSK-3 inhibitor plus insulin $[8,12,45-48]$. It would be very interesting to examine the effect of these factors on HSC division ex vivo in the future.

Wild-type OP9 stromal cells can partially reverse the division defect of Tet 2 knockout (KO) precursors, suggesting that the Tet $2 \mathrm{KO}$ niche also contributes to the hematopoiesis phenotype of Tet $2 \mathrm{KO}$ mouse. It is well established that the stromal niche regulates quiescence, multipotentiality, and self-renewal of HSCs in vivo $[49,50]$. It is also known that the hematopoiesis-specific Cre Mx1-Cre is expressed in niche stromal cells of bone marrow [51]. Thus, the in vivo Tet $2 \mathrm{KO}$ phenotypes might be the combination effect of Tet 2 deletion in precursors and stromal niche cells.

Previous studies demonstrated that deletion of Tet2 in HSCs leads to an increased primitive compartment including both stem and progenitor cells in vivo [23-25]. Our data showed that Tet2 null HSCs underwent more symmetric differentiation than wild-type HSCs ex vivo, suggesting that loss of Tet 2 induces differentiation of hematopoietic precursors in culture. Those dividing Tet2 null precursors in general displayed low GFP intensity. Given that GFP intensity is correlated with "stemness" of precursors, it is very likely that those dividing cells are mostly progenitors. These data are consistent with in vivo studies showing that Tet2 deletion expands both hematopoietic stem cells and progenitor compartments [23-25]. Wild-type OP9 can reverse the phenotype of Tet2 null precursors, indicating that microenvironment contributes to the aberrant dividing pattern of Tet 2 null precursors in culture. Importantly, we also demonstrated that the DNA methyltransferase inhibitor decitabine
(DAC) rescued the division defect of Tet2 knockout, suggesting the DNA methylation is responsible for causing the division defect of precursors. Lastly, we showed that Tet $2^{-1-}$; Flt $3^{\mathrm{ITD}}$ HSCs/HPCs underwent more symmetric renewal division, which is consistent with the idea that some oncogenes influence the balance of symmetric and asymmetric division $[14,27]$. This finding provides a rationale for targeting the abnormal cell division of leukemic precursors as a new therapeutic approach to leukemia.

There are several limitations to the current study, the most important one being the specificity of the Evi1GFP reporter. In our transplantation experiment, only one-third of the mice were successfully engrafted upon injecting 100 Evi1-GFP ${ }^{+}$cells. The engraftment ability of Evi1-GFP ${ }^{+}$cells is weaker in comparison to sorted HSCs, indicating that not all $\mathrm{GFP}^{+}$cells are HSCs in Evi1-GFP mouse. Consistently, we showed that GFP intensity is correlated with "stemness" of precursors. Although it is still important to investigate the behaviors of all hematopoietic precursors in culture, it would be also critical to isolate bona fide HSCs and monitor their dividing behavior in our system in future. The second limitation is that we only tracked precursors dividing for $24 \mathrm{~h}$ in this study. It is known that the time until the first division for HSCs is on average $45 \mathrm{~h}$ ex vivo [52]. In future, the long-term time-lapse tracking of precursors will provide more valuable information about selfrenewal and differentiation features of HSCs in culture.

\section{Conclusions}

In summary, we demonstrated that Evil-GFP mouse is a faithful reporter of hematopoietic precursors ex vivo. A cytokine and growth factor (STIF) combination promotes symmetric renewal of precursors in culture whereas OP9 stromal cells balance the renewal and differentiation of precursors. We found that Tet 2 deletion leads to increased symmetric differentiation of precursors ex vivo. Tet $2^{-1} ; F L T 3^{\text {ITD }}$ AML precursors primarily underwent symmetric renewal divisions in culture. Importantly, we found that inhibiting DNA methylation can reverse the aberrant division phenotypes of Tet $2^{-/-}$and $T e t 2^{-/-} ; F L T 3^{\text {ITD }}$ precursors, suggesting that abnormal DNA methylation plays an important role in controlling (pre-)leukemic precursor fate decision ex vivo.

\section{Additional files}

Additional file 1: Movie S1. GFP ${ }^{+}$precursors underwent symmetric renewal ex vivo. The representative time-lapse movie of $\mathrm{GFP}^{+}$precursors that underwent symmetric renewal during $24 \mathrm{~h}$ in culture. (AVI $1022 \mathrm{~kb}$ )

Additional file 2: Movie S2. GFP ${ }^{+}$precursors underwent symmetric differentiation ex vivo. The representative time-lapse movie of GFP+ precursors that underwent symmetric differentiation during $24 \mathrm{~h}$ in culture. (AVI 1118 kb) 
Additional file 3: Movie S3. $\mathrm{GFP}^{+}$precursors underwent asymmetric division ex vivo. The representative time-lapse movie of $\mathrm{GFP}^{+}$precursors that underwent asymmetric division during $24 \mathrm{~h}$ in culture. (AVI 798 kb)

Additional file 4: Figure S1. OP9 stromal cells contribute to the fate decision of precursors ex vivo. (a) The frequency of symmetric self-renewal, symmetric differentiation, and asymmetric division of $\mathrm{GFP}^{+}$precursors from wild-type mouse treated with OP9 supernatant during $24 \mathrm{~h}$ is shown. The data are a summary from three independent experiments. Error bars represent standard error of the mean (SEM). (b) The frequency of symmetric self-renewal, symmetric differentiation, and asymmetric division of GFP ${ }^{+}$ precursors from wild-type mouse seeded on irradiated OP9 cells during $24 \mathrm{~h}$ is shown. The data are a summary from three independent experiments. Error bars represent SEM. (PDF $420 \mathrm{~kb}$ )

Additional file 5: Figure S2. Tet2 loss leads to increased hematopoietic stem cell in mouse bone marrow. (a) The representative data of FACS analysis of wild-type and Tet2 knockout HSCs. The cells were stained with antibodies to lineage, Sca1, and c-Kit markers. The lineage negative population was gated first. Numbers indicate percent cells within Lin-c-Kit ${ }^{+} \mathrm{Sca}{ }^{+}$gates. (b) The representative FACS data of $\mathrm{GFP}^{+}$population from wild-type and Tet $2^{-1-}$ mouse. The lineage, Sca1, and c-Kit markers were stained and gated first. The $\mathrm{GFP}^{+}$population from Lin-Scal ${ }^{+} \mathrm{C}-\mathrm{Kit}^{+}$was compared between wild-type and $\mathrm{Tet}^{-1-}$ mouse. (PDF $642 \mathrm{~kb}$ )

Additional file 6: Figure S3. The fluorescence intensity of dividing $\mathrm{Tet}^{-/-}$and $\mathrm{Tet}^{-/-} ; \mathrm{Flt}^{\mathrm{ITD}}$ dividing HSCs. (a) The GFP pixel intensity unit (PIU) of Tet2 ${ }^{-/}$dividing HSCs was compared with wild-type control. (b) The GFP PIU of $\mathrm{Tet}^{-{ }^{-1}}$; FIt $3^{\text {TD }}$ dividing HSCs was compared with wild-type control. (PDF $552 \mathrm{~kb}$ )

\section{Abbreviations}

AML: Acute myeloid leukemia; DAC: 5-Aza-2'-deoxycytidine DMEM: Dulbecco's modified Eagle's medium; DNMT: DNA methyltransferase enzyme; Evi1: Ecotropic viral integration site 1; FGF: Fibroblast growth factor; FLT3-L: FMS-like tyrosine kinase-3 ligand; GFP: Green fluorescent protein; HSC: Hematopoietic stem cell; HSPC: Hematopoietic stem/progenitor cells; IGF: Insulin-like growth factor; ITD: Internal tandem duplication; KO: Knockout; LSC: Leukemia stem cell; LSK: Lin- Sca $1^{+}{ }^{-}-k_{i t}{ }^{+}$cells; PE: Phycoerythrin; PIU: Pixel intensity unit; SCF: Stem cell factor; STIF: SCF + TPO + IGF-2 + FGF-1; TET: Ten-eleven translocation; TPO: Thrombopoietin

\section{Acknowledgements}

We thank Dr. Peter Klein at the University of Pennsylvania (UPenn) and Drs. Yuri Persidsky, Jean-Pierre Issa, Yi Zhang, and Nancy L. Reichenbach at Temple University Lewis Katz School of Medicine for their insightful comments and discussion. We especially thank Hanghang Zhang and Roshanak Razmpour at Temple University Lewis Katz School of Medicine for providing experimental reagents and technical assistance. We thank all the members of the Klein laboratory for their help and discussion. We specially thank the Cell \& Developmental Biology (CDB) Microscopy core facility of UPenn for providing us with their service, especially Dr. Andrea Stout. We also thank the flow cytometry and sorting core facilities of Temple University and UPenn for providing us with services.

\section{Funding}

DL is supported by a grant from National Natural Science Foundation of China (81500244). This work was supported by grants from the NHLBI (R00 HL107747-04) and a seed grant from Temple University Lewis Katz School of Medicine to $\mathrm{JH}$.

\section{Availability of data and materials}

All data generated and/or analyzed during this study are available from the corresponding author upon reasonable request.

\section{Authors' contributions}

YW, HT, WC, DL, ZL, CW, and JH performed the experiments and analyzed the data; DB, LF, HW, and HS provided crucial input for the project; TS and MK provided Evi1-GFP mouse; JH designed and supervised the study; $\mathrm{YW}$ and $\mathrm{JH}$ wrote the manuscript. All authors read and approved the final manuscript.

\section{Ethics approval}

Animals used in this study were housed in a specific pathogen-free animal facility and all experimental procedures were approved by IACUC of Temple University School of Medicine (IACUC approval number: 4585).

\section{Consent for publication}

Not applicable.

\section{Competing interests}

The authors declare that they have no competing interests.

\section{Publisher's Note}

Springer Nature remains neutral with regard to jurisdictional claims in published maps and institutional affiliations.

\section{Author details}

${ }^{1}$ Department of Physiology \& Pathophysiology, School of Basic Medical Science, Peking University, Beijing, People's Republic of China. ${ }^{2}$ Department of Pathology and Laboratory Medicine, Lewis Katz School of Medicine, Temple University, Philadelphia, PA 19140, USA. ${ }^{3}$ Jiangsu Institute of Hematology, The First Affiliated Hospital of Soochow University, Suzhou, People's Republic of China. ${ }^{4}$ Department of Medicine (Hematology-Oncology), University of Pennsylvania School of Medicine, Philadelphia, Pennsylvania, USA. ${ }^{5}$ Fox Chase Cancer Center, Philadelphia, Pennsylvania, USA. ${ }^{6}$ Department of Hematology and Oncology, University of Tokyo, Bunkyo-ku, Tokyo 113-8655, Japan. ${ }^{7}$ Department of Physiology and Pathophysiology, School of Basic Medical Science, Tianjin Medical University, Tianjin 300070, People's Republic of China. ${ }^{8}$ Center for Metabolic Disease Research, Department of Pharmacology, Lewis Katz School of Medicine, Temple University, Philadelphia, USA. ${ }^{9}$ Department of Microbiology, University of Pennsylvania School of Medicine, Philadelphia, Pennsylvania USA. ${ }^{10}$ Department of Prenatal Diagnosis, Obstetrics and Gynecology Hospital Affiliated to Nanjing Medical University, Nanjing 210004, Jiangsu, People's Republic of China.

Received: 22 August 2017 Revised: 19 December 2017 Accepted: 28 December 2017 Published online: 23 January 2018

\section{References}

1. Seita J, Weissman IL. Hematopoietic stem cell: self-renewal versus differentiation. Wiley Interdiscip Rev Syst Biol Med. 2010;2(6):640-53.

2. Eaves CJ. Hematopoietic stem cells: concepts, definitions, and the new reality. Blood. 2015:125(17):2605-13.

3. Morrison SJ, Kimble J. Asymmetric and symmetric stem-cell divisions in development and cancer. Nature. 2006;441(7097):1068-74.

4. Tajbakhsh S, Rocheteau P, Le Roux I. Asymmetric cell divisions and asymmetric cell fates. Annu Rev Cell Dev Biol. 2009:25:671-99.

5. Kataoka K, Kurokawa M. Ecotropic viral integration site 1, stem cell self-renewal and leukemogenesis. Cancer Sci. 2012;103(8):1371-7.

6. Goyama S, Yamamoto G, Shimabe M, Sato T, Ichikawa M, Ogawa S, Chiba S, Kurokawa M. Evi-1 is a critical regulator for hematopoietic stem cells and transformed leukemic cells. Cell Stem Cell. 2008;3(2):207-20.

7. Kataoka K, Sato T, Yoshimi A, Goyama S, Tsuruta T, Kobayashi H, Shimabe M, Arai S, Nakagawa M, Imai Y, et al. Evi1 is essential for hematopoietic stem cell self-renewal, and its expression marks hematopoietic cells with long-term multilineage repopulating activity. J Exp Med. 2011;208(12):2403-16.

8. Dahlberg A, Delaney C, Bernstein ID. Ex vivo expansion of human hematopoietic stem and progenitor cells. Blood. 2011;117(23):6083-90.

9. Hofmeister CC, Zhang J, Knight KL, Le P, Stiff PJ. Ex vivo expansion of umbilical cord blood stem cells for transplantation: growing knowledge from the hematopoietic niche. Bone Marrow Transplant. 2007;39(1):11-23.

10. Zhang CC, Lodish HF. Cytokines regulating hematopoietic stem cell function. Curr Opin Hematol. 2008;15(4):307-11.

11. Zhang CC, Lodish HF. Murine hematopoietic stem cells change their surface phenotype during ex vivo expansion. Blood. 2005;105(11):4314-20.

12. Zhang CC, Kaba M, Ge G, Xie K, Tong W, Hug C, Lodish HF. Angiopoietin-like proteins stimulate ex vivo expansion of hematopoietic stem cells. Nat Med. 2006;12(2):240-5

13. Nakano T, Kodama H, Honjo T. Generation of lymphohematopoietic cells from embryonic stem cells in culture. Science. 1994;265(5175):1098-101. 
14. Wu M, Kwon HY, Rattis F, Blum J, Zhao C, Ashkenazi R, Jackson TL, Gaiano $\mathrm{N}$, Oliver T, Reya T. Imaging hematopoietic precursor division in real time. Cell Stem Cell. 2007;1(5):541-54.

15. Butler JS, Dent SY. The role of chromatin modifiers in normal and malignant hematopoiesis. Blood. 2013;121(16):3076-84.

16. Cullen SM, Mayle A, Rossi L, Goodell MA. Hematopoietic stem cell development: an epigenetic journey. Curr Top Dev Biol. 2014;107:39-75.

17. Cedar H, Bergman Y. Epigenetics of haematopoietic cell development. Nat Rev Immunol. 2011;11(7):478-88.

18. Beerman I, Rossi DJ. Epigenetic regulation of hematopoietic stem cell aging. Exp Cell Res. 2014;329(2):192-9.

19. He YF, Li BZ, Li Z, Liu P, Wang Y, Tang Q, Ding J, Jia Y, Chen Z, Li L, et al. Tet-mediated formation of 5-carboxylcytosine and its excision by TDG in mammalian DNA. Science. 2011;333(6047):1303-7.

20. Tahiliani M, Koh KP, Shen Y, Pastor WA, Bandukwala H, Brudno Y, Agarwal S, lyer LM, Liu DR, Aravind L, et al. Conversion of 5-methylcytosine to 5hydroxymethylcytosine in mammalian DNA by MLL partner TET1. Science. 2009;324(5929):930-5.

21. Ito S, Shen L, Dai Q, Wu SC, Collins LB, Swenberg JA, He C, Zhang Y. Tet proteins can convert 5-methylcytosine to 5-formylcytosine and 5carboxylcytosine. Science. 2011:333(6047):1300-3.

22. An J, Gonzalez-Avalos E, Chawla A, Jeong M, Lopez-Moyado IF, Li W, Goodell MA, Chavez L, Ko M, Rao A. Acute loss of TET function results in aggressive myeloid cancer in mice. Nat Commun. 2015;6:10071.

23. Ko M, Bandukwala HS, An J, Lamperti ED, Thompson EC, Hastie R, Tsangaratou A, Rajewsky K, Koralov SB, Rao A. Ten-Eleven-Translocation 2 (TET2) negatively regulates homeostasis and differentiation of hematopoietic stem cells in mice. Proc Natl Acad Sci U S A. 2011;108(35):14566-71.

24. Moran-Crusio K, Reavie L, Shih A, Abdel-Wahab O, Ndiaye-Lobry D, Lobry C, Figueroa ME, Vasanthakumar A, Patel J, Zhao X, et al. Tet2 loss leads to increased hematopoietic stem cell self-renewal and myeloid transformation. Cancer Cell. 2011:20(1):11-24.

25. Kunimoto H, Fukuchi Y, Sakurai M, Sadahira K, Ikeda Y, Okamoto S, Nakajima H. Tet2 disruption leads to enhanced self-renewal and altered differentiation of fetal liver hematopoietic stem cells. Sci Rep. 2012;2:273.

26. Shih AH, Jiang Y, Meydan C, Shank K, Pandey S, Barreyro L, Antony-Debre I, Viale A, Socci N, Sun Y, et al. Mutational cooperativity linked to combinatorial epigenetic gain of function in acute myeloid leukemia. Cancer Cell. 2015;27(4):502-15.

27. Bajaj J, Zimdahl B, Reya T. Fearful symmetry: subversion of asymmetric division in cancer development and progression. Cancer Res. 2015;75(5):792-7.

28. Lee BH, Tothova Z, Levine RL, Anderson K, Buza-Vidas N, Cullen DE, McDowell EP, Adelsperger J, Frohling S, Huntly BJ, et al. FLT3 mutations confer enhanced proliferation and survival properties to multipotent progenitors in a murine model of chronic myelomonocytic leukemia. Cancer Cell. 2007;12(4):367-80.

29. Huang J, Zhang Y, Bersenev A, O'Brien WT, Tong W, Emerson SG, Klein PS Pivotal role for glycogen synthase kinase-3 in hematopoietic stem cell homeostasis in mice. J Clin Invest. 2009:119(12):3519-29.

30. Huang J, Nguyen-McCarty M, Hexner EO, Danet-Desnoyers G, Klein PS Maintenance of hematopoietic stem cells through regulation of Wnt and mTOR pathways. Nat Med. 2012;18(12):1778-85.

31. Ho AD. Kinetics and symmetry of divisions of hematopoietic stem cells. Exp Hematol. 2005;33(1):1-8.

32. Schroeder T. Asymmetric cell division in normal and malignant hematopoietic precursor cells. Cell Stem Cell. 2007;1(5):479-81.

33. Heike T, Nakahata T. Ex vivo expansion of hematopoietic stem cells by cytokines. Biochim Biophys Acta. 2002;1592(3):313-21.

34. Copelan EA. Hematopoietic stem-cell transplantation. N Engl J Med. 2006; 354(17):1813-26

35. Oh P, Lobry C, Gao J, Tikhonova A, Loizou E, Manent J, van Handel B, Ibrahim S, Greve J, Mikkola H, et al. In vivo mapping of notch pathway activity in normal and stress hematopoiesis. Cell Stem Cell. 2013;13(2):190-204.

36. Maillard I, Koch U, Dumortier A, Shestova O, Xu L, Sai H, Pross SE, Aster JC, Bhandoola A, Radtke F, et al. Canonical notch signaling is dispensable for the maintenance of adult hematopoietic stem cells. Cell Stem Cell. 2008; 2(4):356-66

37. Lin H. The stem-cell niche theory: lessons from flies. Nat Rev Genet. 2002; 3(12):931-40.

38. de Cuevas M, Matunis EL. The stem cell niche: lessons from the Drosophila testis. Development. 2011;138(14):2861-9.
39. Egger B, Gold KS, Brand AH. Regulating the balance between symmetric and asymmetric stem cell division in the developing brain. Fly. 2011;5(3):237-41.

40. Crittenden SL, Leonhard KA, Byrd DT, Kimble J. Cellular analyses of the mitotic region in the Caenorhabditis elegans adult germ line. Mol Biol Cell. 2006;17(7):3051-61.

41. Huang $S$, Law P, Francis K, Palsson BO, Ho AD. Symmetry of initial cell divisions among primitive hematopoietic progenitors is independent of ontogenic age and regulatory molecules. Blood. 1999;94(8):2595-604.

42. Ema $H$, Takano $H$, Sudo $K$, Nakauchi $H$. In vitro self-renewal division of hematopoietic stem cells. J Exp Med. 2000;192(9):1281-8.

43. Punzel M, Liu D, Zhang T, Eckstein V, Miesala K, Ho AD. The symmetry of initial divisions of human hematopoietic progenitors is altered only by the cellular microenvironment. Exp Hematol. 2003;31(4):339-47.

44. Giebel B, Bruns I. Self-renewal versus differentiation in hematopoietic stem and progenitor cells: a focus on asymmetric cell divisions. Curr Stem Cell Res Ther. 2008;3(1):9-16

45. Walasek MA, Bystrykh L, van den Boom V, Olthof S, Ausema A, Ritsema M, Huls G, de Haan G, van Os R. The combination of valproic acid and lithium delays hematopoietic stem/progenitor cell differentiation. Blood. 2012; 119(13):3050-9.

46. Rentas S, Holzapfel NT, Belew MS, Pratt GA, Voisin V, Wilhelm BT, Bader GD, Yeo GW, Hope KJ. Musashi-2 attenuates AHR signalling to expand human haematopoietic stem cells. Nature. 2016;532(7600):508-11.

47. Fares I, Chagraoui J, Gareau Y, Gingras S, Ruel R, Mayotte N, Csaszar E, Knapp DJ, Miller P, Ngom M, et al. Cord blood expansion. Pyrimidoindole derivatives are agonists of human hematopoietic stem cell self-renewal. Science. 2014;345(6203):1509-12.

48. Boitano AE, Wang J, Romeo R, Bouchez LC, Parker AE, Sutton SE, Walker JR, Flaveny CA, Perdew GH, Denison MS, et al. Aryl hydrocarbon receptor antagonists promote the expansion of human hematopoietic stem cells. Science. 2010;329(5997):1345-8.

49. Crane GM, Jeffery E, Morrison SJ. Adult haematopoietic stem cell niches. Nat Rev Immunol. 2017:17(9):573-90.

50. Morrison SJ, Scadden DT. The bone marrow niche for haematopoietic stem cells. Nature. 2014;505(7483):327-34.

51. Joseph C, Quach JM, Walkley CR, Lane SW, Lo Celso C, Purton LE. Deciphering hematopoietic stem cells in their niches: a critical appraisal of genetic models, lineage tracing, and imaging strategies. Cell Stem Cell. 2013;13(5):520-33.

52. Roch A, Giger S, Girotra M, Campos V, Vannini N, Naveiras O, Gobaa S, Lutolf MP. Single-cell analyses identify bioengineered niches for enhanced maintenance of hematopoietic stem cells. Nat Commun. 2017;8(1):221.

\section{Submit your next manuscript to BioMed Central and we will help you at every step:}

- We accept pre-submission inquiries

- Our selector tool helps you to find the most relevant journal

- We provide round the clock customer support

- Convenient online submission

- Thorough peer review

- Inclusion in PubMed and all major indexing services

- Maximum visibility for your research

Submit your manuscript at www.biomedcentral.com/submit
) Biomed Central 